\title{
Analysis of noise suppression in cascaded all-optical regenerators
}

\author{
Mørk, Jesper; Öhman, Filip; Bischoff, Svend
}

Published in:

2002 IEEE/LEOS Annual Meeting Conference Proceedings

Link to article, DOI:

10.1109/LEOS.2002.1133967

Publication date:

2002

Document Version

Publisher's PDF, also known as Version of record

Link back to DTU Orbit

Citation (APA):

Mørk, J., Öhman, F., \& Bischoff, S. (2002). Analysis of noise suppression in cascaded all-optical regenerators. In 2002 IEEE/LEOS Annual Meeting Conference Proceedings (Vol. 1). IEEE.

https://doi.org/10.1109/LEOS.2002.1133967

\section{General rights}

Copyright and moral rights for the publications made accessible in the public portal are retained by the authors and/or other copyright owners and it is a condition of accessing publications that users recognise and abide by the legal requirements associated with these rights.

- Users may download and print one copy of any publication from the public portal for the purpose of private study or research

- You may not further distribute the material or use it for any profit-making activity or commercial gain

- You may freely distribute the URL identifying the publication in the public portal

If you believe that this document breaches copyright please contact us providing details, and we will remove access to the work immediately and investigate your claim. 


\title{
ANALYSIS OF NOISE SUPPRESSION IN CASCADED ALL-OPTICAL REGENERATORS
}

\author{
Jesper Mørk, Filip Öhman and Svend Bischoff \\ COM, Technical University of Denmark, DK-2800 Kgs. Lyngby, Denmark (jm@com.dtu.dk)
}

\begin{abstract}
We derive an approximate analytical expression for the BER of cascaded links with all-optical regenerators and use it for performing a general analysis of the interplay between noise and the non-linearity of the regenerator characteristic.
\end{abstract}

\section{Introduction}

The use of all-optical regenerators in networks may increase the bandwidth and reach, and aflow for more flexible and cost-effective solutions compared to conventional opto-electronic repeaters. The cascading of one hundred all-optical semiconductor MachZehnder interferometers (MZls) has been experimen. tally demonstrated [1]. The noise-redistribution property of an optically controlled $M Z I$ with semiconductor optical amplifiers (SOAs) in the arms rests on the non-linear amplitude reshaping transfer function of the device [2]. The thresholding effect thus leads to a reduction of the rate of error accumulation in a cascade of fiber links with amplifiers for loss compensation. In most cases, a regenerator transfer function with a higher degree of non-linearity, i.e., closer to an ideal step function, is achieved at the expense of a larger amount of noise added by the regenerator. For instance, the cascading of two MZls strongly improves the transfer function [3], but also adds additional noise from the SOAs. In other cases, an increased absorption of the device needs to be counterbalanced by a larger gain, leading to additional noise. In order to evaluate novel regenerator ideas, see e.g. [4], and improve the designs, it is thus important to understand this compromise.

The analysis of cascaded non-linear regenerators is strongly complicated by the development of nongaussian noise distributions along the cascade. A matrix method has been developed for performing such noise transtormations [5], but its numerical nature makes it difficult to perform a general analysis. The purpose of this paper is twofold: Firstly, we derive an approximate analytical expression for the BER of a cascade of regenerators. Secondly, we perform a general and comprehensive analysis of $2 R-$ regenerators. The results show how the maximum number of regenerators for a given transmission quality depend on power level, bandwidth, and degree of reshaping.

\section{Theory}

The cascade of fiber links and regenerators, each consisting of an amplifier part and an amplitude reshaping part, is illustrated in Fig. 1. The shape of the time-independent transfer function is in the figure represented by a simple tanh-function with parameter $\gamma$ [4]. For $\gamma=1$ the transfer function is linear with unit slope and for decreasing $\gamma$ it evolves into an ideal step transfer function, which is achieved for $\gamma=0$. An MZl corresponds to a moderate $\gamma \approx 0.65$ [5].

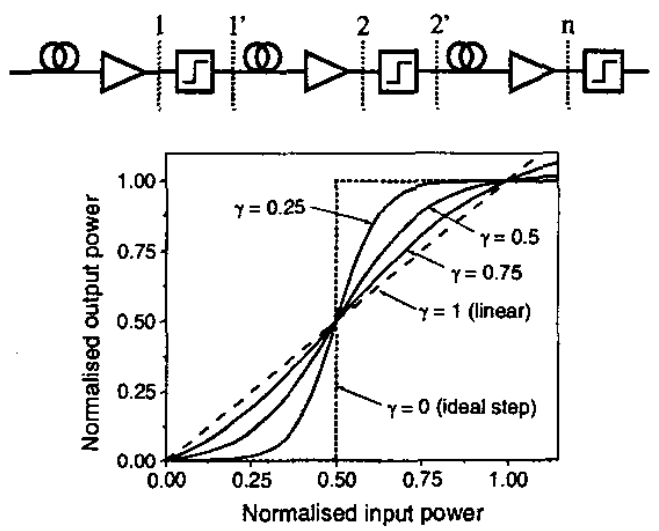

Fig. 1. Cascade of transmission spans with fiber, amplification and reshaping (upper). Regenerator transfer functions for different $\gamma$-values (lower).

In order to derive an approximate analytical result, we consider a step-wise linear transfer function with slopes of $\gamma$ around mark (1) and space (0) levels and a corresponding discontinuity at the threshoid level. It was shown [5] that this function leads to BER values similar to those obtained from the smooth functions in Fig. 1. By assuming initial gaussian noise distributions of the space and mark levels, describing the spontaneous emission noise added by the amplifiers through a noise figure $F_{n}$ and utilizing the special form of the transfer function to transform the distributions across the interfaces 1-1', 2-2', etc., we arrive at an approximate expression for the BER after $N$ segments:

$$
B E R_{N} \equiv \frac{N}{\sqrt{2 \pi Q_{0}^{2} / F_{n}}} \sqrt{\frac{\gamma^{2}-1}{\gamma^{2 N}-1}} \exp \left(-\frac{Q_{0}^{2}}{2 F_{n}} \frac{\gamma^{2}-1}{\gamma^{2 N}-1}\right) \text { (1) }
$$

The $\mathrm{Q}$-value of the signal entering the cascade is given by $Q_{0}$. For a shot-noise limited signal, $Q_{0}^{2}=P_{i n} /\left(4 h v B_{e}\right)$, with $P_{i n}$ denoting mean input power, $h \nu$ photon energy, and $B_{\theta}$ effective optical bandwidth, which exceeds the bitrate but may be limited by filtering. We have, for simplicity, assumed 
identical noise contributions for space and mark levels, and jitter and fiber dispersion are neglected.

Fig. 2 compares the analytical result (1) with a direct numerical simulation, based on [5], of the simplified transfer function taking full account of the evolution of non-gaussian probability distribution functions along the cascade. Good quantitative agreement is seen for all values of $\gamma_{1}$ and the analytical result thus provides a powerful way of analysing all-optical 2Rregenerators. Notice that detector noise and filtering is not included in the calculation in order to illustrate the noise transformation properties of the link itself.

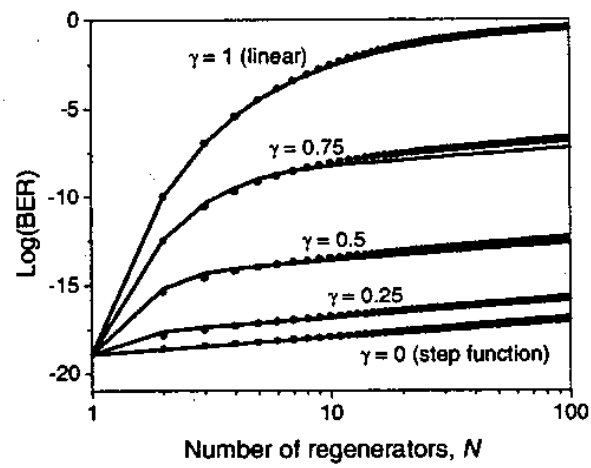

Fig. 2. Comparison of numerical simulation (markers) and analytical expression (solid line) for BER versus number of regenerators. $\left(Q_{0}^{2} / F_{n}=9\right)$.

\section{Results}

From Eq. (1) we may solve for the required value of $\gamma$ to obtain a certain BER for given values of the noise figure and the number of regenerators. Fig. 3 shows this relation for a BER of $10^{-9}$ for two values of $Q_{0}$. The region above a particular curve, corresponding to a fixed number of regenerators, thus represents BERvalues lower than $10^{-9}$, while the region below the curve corresponds to higher BER-values.

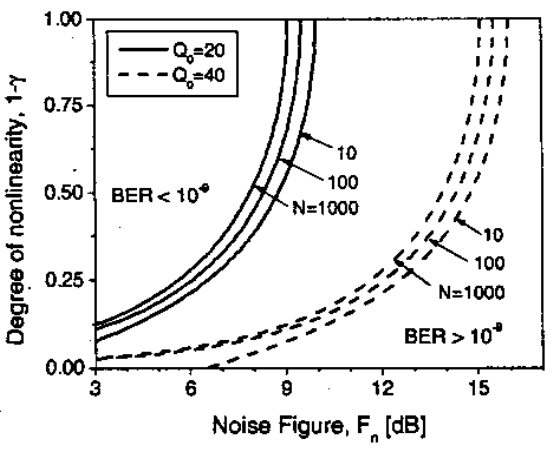

Fig. 3. Regenerator non-linearity, $1-\gamma$, to achieve a BER of $10^{-9}$ versus noise figure $F_{n}$ for links with different numbers of regenerators.
The figure illustrates that an increase of the noise figure may be counteracted by an increased nonlinearity. It may, for example, be seen that for an input Q-value of 40 , a noise figure of $6 \mathrm{~dB}$ requires a $\gamma$ value of 0.95 to cascade 1000 regenerators. An increase of the noise figure to $12 \mathrm{~dB}$ is counteracted by increasing the non-linearity of the transfer function to give a $\gamma$-value of about 0.73 , a modest non-linearity as seen from Fig. 1. For a given device, where the relation between added noise and non-linearity of the transfer function is known, results as those in Fig. 3 can be used to conclude on the benefit of the device.

Fig. 4 plots the minimum value of $Q_{0}^{2} / F_{n}$ to achieve a BER of $10^{-9}$ in dependence of the degree of nonlinearity for different numbers of cascaded links. From such a plot, knowing the effective noise figure of the regenerator, the minimum input Q-value, or minimum input power for a given link bandwidth, can be inferred. For a large number of cascaded links it can be seen that even a modest non-linearity can compensate for a $3 \mathrm{~dB}$ reduction of the noise figure or the input power. For large degrees of non-linearity the curves reflect the slow, nearly linear, increase of BER with number of regenerators.

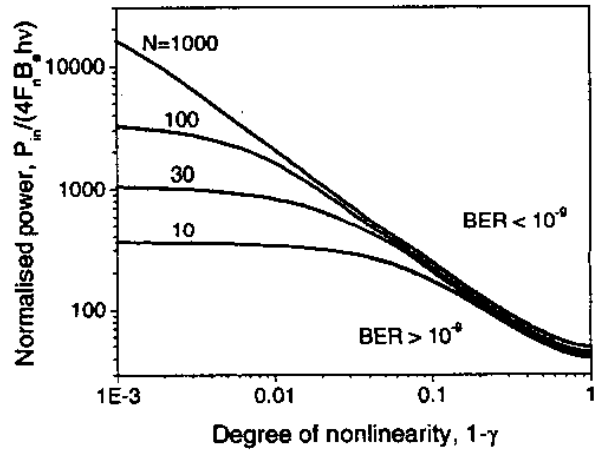

Fig. 4. Minimum value of $Q_{0}^{2} / F_{n}$ to achieve a BER of $10^{-9}$ versus regenerator non-linearity, $1-\gamma$.

\section{Conclusions}

We have derived an approximate analytical expression for the BER of cascaded 2R-regenerators, which is shown to agree weil with numerical simulations. The result is used to analyse in general terms the compromise between the noise added by regenerators and the degree of amplitude reshaping.

\section{References}

1 B. Lavigne et al., Proc. ECOC (2001), p. 290.

2 B. Mikkelsen et al., Electron. Lett., 32 (1996), 566.

3 B. Lavigne et al., Proc. OFC (1999), p. 128.

4 M. L. Nielsen et al., Proc. OFC (2002), TuN2.

5 P. Öhlen et al., IEEE Photon. Technol. Lett., 9 (1997), 1011. 